\title{
Effects of hamstring self-stretches on pelvic mobility in persons with low back pain
}

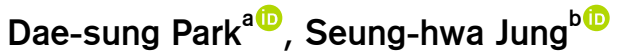 \\ ${ }^{a}$ Department of Physical Therapy, Konyang University, Daejeon, Republic of Korea \\ ${ }^{\mathrm{b}}$ Department of Physical Therapy, The Graduate School of Medical Science, Konyang University, Daejeon, Republic of Korea
}

Objective: The purpose of this study was to examine the effectiveness of pelvic displacement when self-hamstring muscle stretches were applied to persons with low back pain.

Design: Three-group pretest-posttest design.

Methods: Forty persons with low back pain participated in this study. Pelvic tilt angle, hamstring flexibility, Quadruple Visual Analogue Scale (QVAS), Fear Avoidance Beliefs Questionnaire (FABQ), Korea version of the Oswestry Disability Index (KODI) and pelvic mobility were measured at pre-post. All participants were divided into either the pevic anterior tilt group (PAT group, $\mathrm{n}=12$ ), pelvic midrange group (PMR group, $\mathrm{n}=18$ ), or the pelvic posterior tilt group (PPT group, $\mathrm{n}=10$ ). Self-stretching was performed using the pilates ring three times a week for a total of four weeks and the post-test was conducted and compared with the pre-test.

Results: Hamstring flexibility, QVAS, KODI scores were significantly different compared to before the intervention ( $p<0.05)$. The changes in hamstring flexibility of the three groups were significantly different $(p<0.05)$. Changes in KODI and FABQ results of the three groups were not significant. The pelvic posterior tilt range were significantly different in the PMR and PPT groups $(p<0.05)$. The pelvic anterior tilt ranges showed significant differences after stretching in the PPT group $(p<0.05)$.

Conclusions: A large amount of change of hamstring flexibility, pelvic mobility of anterior and posterior tilt test in the PPT group was observed. Furthermore, therapists should consider pelvic displacement of the participant when applying intervention, which may, accordingly, have different effectiveness.

Key Words: Hamstring muscles, Low back pain, Muscle stretching exercises, Pelvis

\section{Introduction}

Anatomically, the spine and the pelvis are connected as a complex, and pelvic displacements related to low back pain include pelvic anterior and posterior inclination [1]. It is a typical pelvic displacement that leads to low back pain, and it plays a role of rotating the pelvis forward through having the lower back extensor muscles acting as cocontractors. On the contrary, the posterior inclination is caused by the cocontraction of the rectus abdominis and external oblique muscles with the gluteus maximus and hamstring muscles, causing the pelvis to rotate backwards. Secondary problems caused by such pelvic displacement include swayback, flatback syndrome, kyphosis, lordosis, and scoliosis. Such an abnormal posture causes a decrease in flexibility due to tension in the spinal column, sacrum fascia, ligaments and joint pockets, and a limitation of pelvic mobility due to tension in the hip flexors and extensors, which can be considered as a major cause of low back pain [2].

The fascia meridian theory is a theory stating that muscles move as a single functional unit across the whole body as a long tension band through the connected fascia by combining adjacent muscle tissues equivalent to a spider web. The sacral nodular ligament is located between the sacrum and

Received: 9 August, 2020 Revised: 27 August, 2020 Accepted: 28 August, 2020

Corresponding author: Dae-sung Park (ORCID https://orcid.org/0000-0003-4258-0878)

Department of Physical Therapy, Konyang University, 158 Gwanjeodong-ro, Seo-gu, Daejeon 35365, Republic of Korea Tel: 82-42-600-8456 Fax: 82-41-600-1098 E-mail: daeric@naver.com

(c) This is an Open-Access article distributed under the terms of the Creative Commons Attribution Non-Commercial License (http://creativecommons.org/licenses/ by-nc/4.0) which permits unrestricted non-commercial use, distribution, and reproduction in any medium, provided the original work is properly cited.

Copyright $\odot 2020$ Korean Academy of Physical Therapy Rehabilitation Science 
the ishcial tuberosity, and is present in one fascial line along the erector spinae and occipital bone to the orbital ridge, and to the sole of the foot along the posterior femur and calf. The length and tension of the muscles for posture maintenance influence each other, and are classified into a superficial posterior path [3]. Based on this, hamstring muscle shortening and decreased flexibility causes back pain [4]. Tension in the hamstring muscles that are attached to the posterior ischial tuberosities of the pelvis can influence the pelvic position [5]. Decreased hamstring flexibility is a major cause of injury and is a very important factor in preventing and managing low back pain because it causes non-specific low back pain or changes in lumbar pelvic rhythm [6-8].

Unbalanced postures, including lumbar pelvic hypertension and mobility limitations, reduces excessive stress on the spine, muscle strength, endurance, and flexibility, and in order to prevent such problems, exercise or stretching to strengthen the abdominal and lumbar muscles and improve flexibility is essential [2,9]. Among them, the effect of hamstring stretches is a topic of constant interest to researchers. Increasing the movement of the torso and legs can occur by releasing muscle tension through stretching the hamstrings, leading to increases hamstring flexibility, straight leg raise test range, and sit-and-reach test range, which aides in relieving and recovery from back pain [10-13].

In patients with low back pain, static stretching of the hamstrings did not show a significant difference in the measurement of the pelvic inclination, but it assisted in increasing the range of the straight leg raise [14]. Some previous studies reported that there was no significant difference in lumbar lordosis between the low back pain group and the non-low back pain group $[15,16]$. Another study reported that lumbar lordosis was decreased in the low back pain group and that the female patients had greater lordosis than male patients [17]. Another study reported that the low back pain group showed increased lumbar lordosis compared to the non-low back pain group [18].

Based on these results, arguments on the correlation between low back pain and pelvic displacement are varied and are not clear. Therefore, it should be considered that even patients with low back pain with the same symptoms may have different pelvic displacements. Therefore, this study was conducted to compare the effectiveness of hamstring strentching on low back pain between the neutral pelvic, anterior pelvic and posterior pelvic groups.

\section{Methods}

\section{Research participants}

This study included 40 patients who visited the physical therapy room department of Phil hospital of Korean medicine located in Daejeon Metropolitan City through outpatient treatment for chronic low back pain. The criteria for selection of the study participants were those who had experienced back pain for the first time and had been experiencing for more than 3 months, those who had a Quadruple Visual Analogue Scale (QVAS) of 40 or more for their current low back pain, and those without radiating pain. Those who had experienced or currently fractured a vertebrae, those who had surgical experience of the vertebrae, those who had experienced or currently fractured their hip joint, and those diagnosed with lumbar disc herniation and stenosis were excluded from the study.

\section{Research procedure}

This study was a comparative study based on three groups before and after 4 weeks of intervention. The participants' pelvic inclination was compared and classified into $\leq 5^{\circ}$ posterior inclination, $6^{\circ}-10^{\circ}$ neutral, and $\geq 11^{\circ}$ anterior inclination. This subjects were classified into three groups based on the pelvic incidence, which is a representative anatomical index of the spine and pelvis, and the measured values of the previous studies were used to analyze the difference between the sagittal spine indices [19].

The participants pelvic tilt (Anterior superior iliac spinePosterior superior iliac spine, ASIS-PSIS), hamstrings flexibility test using an inclinometer, the 4 items QVAS, psychosocial level test (FABQ), and the low back pain dysfunction level test (KODI) was used to determine the degree of back pain, and pelvic mobility was measured using a Sensbalance Therapy Cushion (STC).

Then, starting from a supine hook-lying position, the knee joint was extended while the ankle joint was fixed using a pilates ring, and the exercise was performed to maintain the knee joint within the maximum range for 30 seconds. In order to selectively stretch the hamstrings, the stretches were performed for 3 sets of 5 times per leg in 3 directions of adduction, neutral, and abduction, and a rest period of $10 \mathrm{sec}-$ onds was provided between each exercise set (Figure 1). Intervention was conducted three times a week for a total of 4 weeks, and post-tests were performed. Prior to the experiment, all participants fully understood the contents of this study and provided their informed consent. This study was 
approved by the Institutional Bioethics Committee of the of Konyang University (IRB No. KYU-2019-332-01).

\section{Measurement and evaluation method}

\section{Pelvic tilt assessment}

In order to group all participants according to the pelvic tilt measurements, the angle between the line connecting the right upper ASIS and the PSIS and the horizontal line was measured.

A posture meter (Posturemeter; Spomedic healthcare, Midvale, UT, 2004) was used to measure the pelvic tilt, which means a $2^{\circ}$ inclination per scale (Figure 2 ). The normal pelvic tilt range is considered to be $0^{\circ}$ to $11.3^{\circ} \pm 4.3^{\circ}$ [20].

\section{Measurement of flexibility of the hamstring muscle}

Active knee extension was assessed with the participants lying in supine position. To limit the movement of the pelvis, a belt was used to fix both ASISs.

With both knees flexed, the hip joint was flexed to 90 degrees, and the legs were placed on a wooden box previously installed. In this position, the right knee was actively

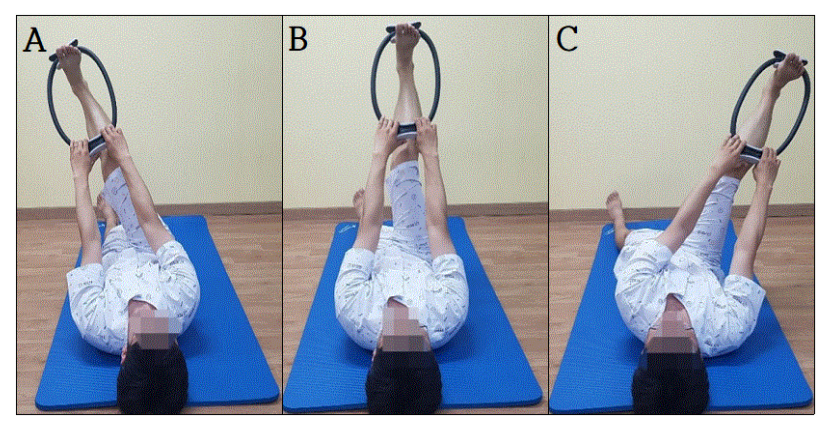

Figure 1. Hamstring stretching. (A) Biceps femoris. (B) Semitendinosus. (C) Semimembranosus.

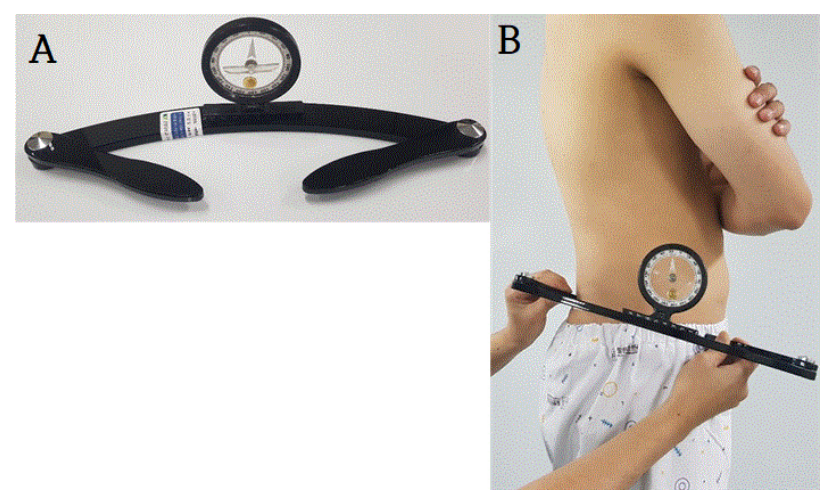

Figure 2. (A) Posturemeter. (B) Measurement of pelvic tilt angle. extended. While stretching the knee, the ankle was in neutral position. For the measurement, a smartphone goniometer application (Clinometer + bubble level; Plaincode, Stephanskirchen, Germany) was used, and it was fixed with a strap $2 \mathrm{~cm}$ above the malleolus of the ankle. With the goniometer set at $0^{\circ}$, the maximum active knee extension angle was measured 3 times and the average value was recorded (Figure 3). The intra-measure reliability of this test method wasreported as $\mathrm{r}=0.86-0.99$, and the inter-measure reliability was $\mathrm{r}=0.76-0.89[21,22]$.

\section{Quadruple visual analogue scale}

A 4-item QVAS was used to objectify the subjective back pain level reported by the patients. It consists of a total of 4 questions: current pain level, average pain level, mildest pain level, and most severe pain level [23]. Each question is marked with a ' $\mathrm{V}$ ' on a $10 \mathrm{~cm}$ horizontal line. Each $1 \mathrm{~cm}$ is scored as 1 point, the scores of the 4 questions are summed and averaged, and the total score is calculated by multiplying by 10 .

In this test, the intra-measure reliability was reported as $\mathrm{r}=0.76-0.84$ [24]. The higher the QVAS score, the more severe the pain.

\section{Psychosocial level test}

The FABQ level test used to evaluate the psychosocial level of the study participants. The FABQ is a questionnaire that evaluates the effect of fear related to pain on physical and occupational activities.

In this study, a questionnaire for fear avoidance response that was translated in Korean was used.

It consists of 5 items related to physical activity and 11 items related to occupational work, and out of a total of 16 items, 5 items $(2,8,13,14,16)$ are not used when adding up after the questionnaire evaluation. This evaluation was calculated with a total score of 66 , and the higher the score, the

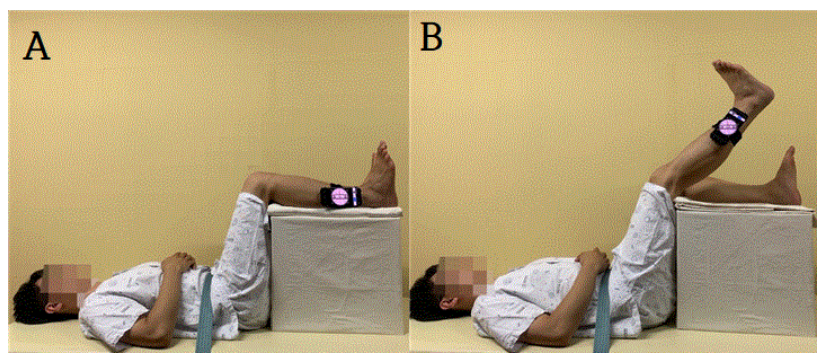

Figure 3. Measurement of hamstring flexibility. (A) Start. (B) Finish. 
stronger the degree of fear avoidance reaction of the patient. The test retest reliability of this test was reported as $\mathrm{r}=0.95$ [25].

\section{Low back pain dysfunction level test}

The KODI was used to evaluate the degree of dysfunction due to low back pain. The KODI consists of a total of 10 areas (pain level, personal hygiene, object lifting, walking, sitting, standing, sex life, sleeping, social activity, travel), and the level of discomfort or disability that the patient feels is indicated. The total score is 50 points, and the evaluation score of the patient was divided by the total score and converted into a percentage. The test-retest reliability of the KODI is high at $r=0.9$. The higher the score, the lower the level of functional performance due to back pain [26].

\section{Pelvic mobility assessment}

The STC (Sensbalance Therapy Cushion; Sensamove Inc., Groessen, Netherlands) was used in order to evaluate pelvic mobility. Data storage and processing were stored through the Pedalo-Sensamove-Balance-Test Pro software (Sensamove Inc.). STC is a device that displays the position of the center of gravity on a monitor in real time. In this study, after placing the STC on a flat chair, the participant was instructed to sit comfortably, and a wooden box with an appropriate height was placed on the sole of the foot so that the leg could be bent $90^{\circ}$. While maintaining a comfortable sitting posture, the Calibrate button was pressed to place the center of gravity displayed on the monitor in the center.

Next, in order to measure the range of motion of the pelvis, the inclination of the pelvis in the front, back, left and right direction was instructed.

At this time, in order to minimize the movement of the trunk and induce pure movement of the pelvis, both hands were held at the bottom of the chair (Figure 4). The greater the mobility, the greater the distance of movement, and the measurement value increases.

This was performed with the monitor covered to prevent visual feedback. The test-retest reliability of this evaluation tool was reported as $\mathrm{r}=0.67-0.84$ [27].

\section{Statistical analysis}

Descriptive statistics were used for the general characteristics of the study participants.

The Wilcoxon signed rank test was used to determine the pre- and post-intervention changes in the measurement variables for each group, and it was judged that there was a stat- istically significant difference when the $p$-value was 0.05 . The Kruskal-Wallis test was used to compare the outcome variables between each group, and when the $p$-value was 0.05 , it was judged as a statistically significant difference, and when the $p$-value was less than 0.01 using the Bonferroni correction by post hoc analysis, it was judged that there was one difference. The study analysis was performed using the PASW Statistics for Windows, Version 18.0 (SPSS Inc., Chicago, IL, USA).

\section{Results}

A total of 40 participants were classified into 12 pelvic anterior tilt group, 18 pelvic midrange (PMR) group, and 10 pelvic posterior tilt (PPT) group. Among the general medical characteristics of the participants, there was a significant difference between the three groups in mean pelvic inclination $(p<0.01$; Table 1$)$. As a result of analyzing the differences in hamstring flexibility, there was a difference in the amount of change between the groups, but the post-test results were not statistically significant. The changes in hamstring flexibility before and after the intervention were significantly increased in all three groups $(p<0.05)$.

As a result of analyzing the differences at each point of measurement of the QVAS, there was no significant difference between the three groups, and in the analysis of changes within the group before and after the intervention, all three groups showed a significant decrease $(p<0.05)$.

As a result of analyzing the differences in measurement time point of the KODI, there was no difference between

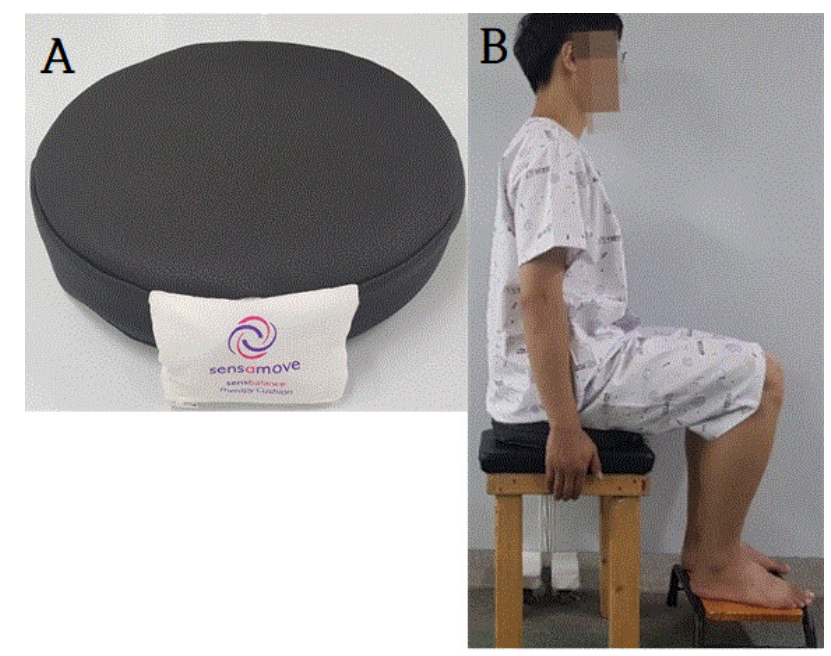

Figure 4. (A) Sensbalance therapy cushion. (B) Setting for measuring pelvic mobility. 
groups. As a result of analyzing the changes within the groups before and after the intervention, all three groups showed a significant decrease $(p<0.05)$.

As a result of analyzing the differences between groups at each point of measurement of FABQ and changes within the groups before and after intervention, there was no significant difference (Table 2).

As a result of analyzing the difference between the groups in anterior pelvic tilt range, there was a difference between groups in the amount of change, but the post-test results were not statistically significant. As a result of analyzing the changes in the anterior tilt range within the group before and after the intervention, there was a significant increase in the PPT group $(p<0.05)$.

As a result of analyzing the differences between groups in PPT range, there was no significant difference. As a result of analyzing the changes within the groups before and after the intervention, there was a significant increase in the PMR and PPT groups $(p<0.05)$.

As a result of analyzing the differences between the groups

Table 1. General characteristics of the participants

$(\mathrm{N}=40)$

\begin{tabular}{lccccc}
\hline \multicolumn{1}{c}{ Variable } & PAT group $(\mathrm{n}=12)$ & PMR group $(\mathrm{n}=18)$ & PPT group $(\mathrm{n}=10)$ & $\mathrm{Z}(p)$ & Post-hoc $^{\mathrm{a}}(p)$ \\
\hline Sex (male/female) & $6 / 6$ & $14 / 4$ & $6 / 4$ & $2.524(0.28)$ & \\
Age $(\mathrm{y})$ & $34.25(5.65)$ & $36.00(8.64)$ & $35.20(9.47)$ & $0.317(0.85)$ & \\
Weight $(\mathrm{kg})$ & $62.41(10.05)$ & $63.88(9.19)$ & $64.00(7.54)$ & $0.585(0.74)$ & \\
Height $(\mathrm{cm})$ & $168.08(8.88)$ & $171.88(9.84)$ & $166.70(6.70)$ & $2.619(0.27)$ & PPT $<$ PMR $<$ PAT $(0.007)$ \\
Pelvic tilt angle $\left(^{\circ}\right)$ & $11.54(0.58)$ & $7.52(1.26)$ & $4.35(0.88)$ & $34.19(0.001)$ & \\
\hline
\end{tabular}

Values are presented as number only or mean (SD).

PAT: pelvic anterior tilt, PMR: pelvic midrange, PPT: pelvic posterior tilt.

${ }^{a}$ Bonferroni correction.

Table 2. Measurement of hamstring flexibility, QVAS, KODI, FABQ

$(\mathrm{N}=40)$

\begin{tabular}{|c|c|c|c|c|c|}
\hline Variable & PAT group $(n=12)$ & PMR group $(n=18)$ & PPT group $(n=10)$ & $\mathrm{Z}(p)$ & $\operatorname{Post}_{-h o c}{ }^{\mathrm{a}}(p)$ \\
\hline \multicolumn{6}{|c|}{ Hamstring flexibility $\left(^{\circ}\right)$} \\
\hline Pre-test & $58.75(3.72)$ & $55.72(4.80)$ & $58.60(3.27)$ & $3.927(0.140)$ & \\
\hline Post-test & $61.17(2.86)$ & $58.17(4.96)$ & $63.10(3.87)$ & & \\
\hline Change value & $2.41(1.35)$ & $2.44(1.62)$ & $4.50(1.60)$ & $7.460(0.024)$ & $\mathrm{PMR}<\operatorname{PPT}(0.026)$ \\
\hline $\mathrm{Z}(p)$ & $-2.517(0.012)$ & $-3.466(0.001)$ & $-2.810(0.005)$ & & \\
\hline \multicolumn{6}{|l|}{ QVAS (score) } \\
\hline Pre-test & $53.16(2.65)$ & $52.83(6.18)$ & $52.70(3.50)$ & $0.056(0.972)$ & \\
\hline Post-test & $50.59(3.36)$ & $50.83(5.90)$ & $49.10(3.10)$ & & \\
\hline Change value & $2.58(2.10)$ & $2.00(2.58)$ & $3.60(2.41)$ & $2.082(0.353)$ & \\
\hline $\mathrm{Z}(p)$ & $-2.701(0.007)$ & $-2.447(0.014)$ & $-2.812(0.005)$ & & \\
\hline \multicolumn{6}{|l|}{ KODI (\%) } \\
\hline Pre-test & $34.50(9.80)$ & $29.67(10.16)$ & $33.80(10.09)$ & $1.945(0.378)$ & \\
\hline Post-test & $32.75(9.26)$ & $27.83(8.86)$ & $30.60(9.27)$ & & \\
\hline Change value & $1.16(1.97)$ & $1.83(2.57)$ & $1.77(2.58)$ & $2.179(0.336)$ & \\
\hline $\mathrm{Z}(p)$ & $-2.410(0.016)$ & $-2.527(0.012)$ & $-2.375(0.018)$ & & \\
\hline \multicolumn{6}{|l|}{ FABQ (score) } \\
\hline Pre-test & $43.42(7.14)$ & $40.94(6.64)$ & $42.90(4.77)$ & $0.477(0.788)$ & \\
\hline Post-test & $42.50(5.97)$ & $40.72(6.79)$ & $41.80(5.26)$ & & \\
\hline Change value & $0.61(1.68)$ & $0.22(0.64)$ & $0.61(2.11)$ & $3.237(0.198)$ & \\
\hline $\mathrm{Z}(p)$ & $-1.473(0.141)$ & $-1.414(0.157)$ & $-1.362(0.173)$ & & \\
\hline
\end{tabular}

Values are presented as mean (SD).

PAT: pelvic anterior tilt, PMR: pelvic midrange PPT: pelvic posterior tilt, QVAS: quadruple visual analogue scale, KODI: Korean version of Oswestry disability index, FABQ: fear avoidance beliefs questionnaire.

${ }^{a}$ Bonferroni correction. 
Table 3. Measurement of pelvic mobility

$(\mathrm{N}=40)$

\begin{tabular}{|c|c|c|c|c|c|}
\hline Variable & PAT group $(n=12)$ & PMR group $(n=18)$ & PPT group $(n=10)$ & $\mathrm{Z}(p)$ & Post-hoc $^{\mathrm{a}}(p)$ \\
\hline \multicolumn{6}{|l|}{ Anterior tilt } \\
\hline Pre-test & $12.79(1.94)$ & $12.21(2.12)$ & $12.54(2.20)$ & $0.899(0.638)$ & \\
\hline Post-test & $13.84(1.15)$ & $13.46(2.83)$ & $15.89(2.18)$ & & \\
\hline Change value & $1.05(0.65)$ & $1.25(0.83)$ & $3.35(0.98)$ & $7.609(0.022)$ & PAT $<$ PPT $(0.029)$ \\
\hline $\mathrm{Z}(p)$ & $-1.892(0.058)$ & $-1.634(0.102)$ & $-2.807(0.005)$ & & \\
\hline \multicolumn{6}{|l|}{ Posterior tilt } \\
\hline Pre-test & $8.23(1.06)$ & $8.42(0.96)$ & $8.12(0.63)$ & $1.018(0.601)$ & \\
\hline Post-test & $9.53(1.32)$ & $9.97(1.52)$ & $11.14(1.30)$ & & \\
\hline Change value & $1.29(0.49)$ & $1.55(0.42)$ & $3.02(0.45)$ & $5.497(0.064)$ & \\
\hline $\mathrm{Z}(p)$ & $-1.804(0.071)$ & $-2.877(0.004)$ & $-2.805(0.005)$ & & \\
\hline \multicolumn{6}{|l|}{ Left tilt } \\
\hline Pre-test & $11.78(1.60)$ & $11.16(2.51)$ & $10.71(1.52)$ & $2.234(0.327)$ & \\
\hline Post-test & $12.58(2.42)$ & $11.84(2.49)$ & $12.50(3.13)$ & & \\
\hline Change value & $0.80(0.83)$ & $0.67(0.83)$ & $1.79(1.10)$ & $1.477(0.478)$ & \\
\hline $\mathrm{Z}(p)$ & $-1.824(0.068)$ & $-1.752(0.08)$ & $-1.785(0.074)$ & & \\
\hline \multicolumn{6}{|l|}{ Right tilt } \\
\hline Pre-test & $11.54(1.65)$ & $12.76(3.13)$ & $11.03(1.67)$ & $2.754(0.252)$ & \\
\hline Post-test & $12.08(1.82)$ & $13.71(3.23)$ & $11.49(1.30)$ & & \\
\hline Change value & $0.54(0.70)$ & $0.95(1.06)$ & $0.49(0.67)$ & $0.224(0.894)$ & \\
\hline $\mathrm{Z}(p)$ & $-0.943(0.346)$ & $-1.310(0.19)$ & $-1.533(0.125)$ & & \\
\hline
\end{tabular}

Values are presented as mean (SD).

PAT: pelvic anterior tilt, PMR: pelvic midrange, PPT: pelvic posterior tilt.

${ }^{a}$ Bonferroni correction.

in left and right pelvic lateral tilt range and the changes within the groups before and after the intervention, there was no significant difference (Table 3).

\section{Discussion}

This study was conducted to compare the effectiveness of the hamstring muscle stretching according to the characteristics of pelvic displacement, and it was found that hamstring flexibility was significantly increased in all three groups.

A study by Handel et al. [28] showed that stretching the hamstrings increased the range of motion of the knee joint by $6.7^{\circ}$, and Bandy and Irion [29] stated that hamstring stretches performed 5 times a week for 6 weeks was effective in increasing the range of motion of the knee joint. In a study by Kim and Kim [30], it was confirmed that the immediate effect of stretching the hamstring muscles caused decreased muscle stiffness and a significant increase in the range of motion of the knee joint. According to a study by Jo et al. [31], the manual extension of the hamstring muscle was effective in increasing the flexibility of the hamstrings while maintaining pelvic neutrality.
Evidence has been suggested through several studies on the mechanism of increasing the range of motion through stretching.

Bandy et al. [32] reported that the perception of the strething was changed due to the decrease in the sensitivity of the pain receptor after stretching, resulting in an increase in tolerance to stretching, and Halbertsma et al. [33] stated that this was due to increased tolerance to discomfort. Magnusson et al. [34] argued that the range of motion was increased due to changes in perception of the stretching and the effect of controlling pain through free nerve endings in muscles and joints. It is believed that this study also showed an increase in the range of motion of the knee joint as a result of these physiological changes.

It was confirmed that the QVAS for evaluating the subjective back pain level significantly decreased in all three groups. According to Lee's study [35], the degree of hamstring flexibility is a factor that can affect the pain level of patients with chronic back pain by reducing pain. In a study by Han et al. [36], a significant increase in hamstring flexibility and a significant decrease in pain level were applied to workers suffering from low back pain after applying the hamstring stretches with pelvic control three times a week 
for 6 weeks.

In this study, an increase of an average of $3.11^{\circ}$ in hamstring flexibility was observed in all three groups. It is thought that the QVAS, which evaluates pain levels, was significantly reduced in this regard.

It was confirmed that the KODI, used for evaluating dysfunction due to low back pain, significantly decreased in all three groups. In a study by Monga and Singh [37], it was found that there was a significant negative correlation as a result of confirming the relationship between KODI levels and the sit-and reach test in patients with chronic low back pain. According to previous studies, the $\mathrm{V}$-sit and reach test was suggested as a representative assessment method for hamstring flexibility [38], and it was confirmed that the range of the sit-and reach test was significantly increased as an immediate effect of stretching the hamstrings [39]. In this study, it was confirmed that hamstring flexibilty was increased through stretching, and the results of previous studies were reflected, and it is thought that the KODI score was significantly reduced. As a result of this study, there was a clear difference in the amount of change in pain levels and hamstring flexibility in the pelvic posterior inclination group. However, the changes in KODI levels was similar between the three groups.

Fritz and Irrgang [40] argued that there is no one-to-one correlation between pain and activity levels (disability index) because disability level measures the difficulty of activities during daily life. It is believed that the difference in the amount of change between groups was not large because the participants that were recruited were familiar with daily living by activities by visiting the outpatient clinic of the hospital.

The FABQ used to assess psychosocial levels showed insignificant results in all three groups. This raises the question of whether the rehabilitation program for the recovery of the psychosocial level of patients with chronic low back pain should focus on hamstring flexibility. Similarly, a study by Marshall et al. [41] showed that there was no significant correlation between hamstring flexibilitys and the FABQ in patients with chronic low back pain. However, according to a study by Kim et al. [42], there was no significant correlation between the pain levels of patients low back pain and the FABQ-vocational activity item, but the FABQ-physical activity item showed a significant positive correlation. In addition, according to a study by Nagrale et al. [43], the application of a rehabilitation program including the hamstring stretching in patients low back pain brought a significant change in the FABQ level. As such, it is unclear whether hamstring flexibility should be considered in back pain rehabilitation programs to recover the psychosocial level, as claims on the association between the hamstring flexibility and FABQ have not yet been clear.

As a result of evaluating pelvic mobility, there was a significant difference in the anterior and posterior inclination ranges in the posterior tilt group, and a significant difference in the posterior tilt range in the pelvic neutral range group.

Overactivation of the hamstring muscle inhibits the activity of the gluteus maximus muscle, thereby changing the muscle mobilization pattern and transforming the movement of the pelvis [44]. The long-term contraction of the hamstrings causes a change in the motion of the lumbar-pelvic rhythm, among which, particularly, the anterior tilt of the pelvis is limited [45].

Based on these contents, in this study, it is thought that increasing flexibility through stretching the hamstring muscles had an effect on the increase in the range of the anterior and posterior pelvic tilt.

However, among the variables for evaluating pelvic mobility, the range of left and right pelvic tilt did not show any significant change.

This is thought to be the result of reflecting the difference in the motion surface in which the action occurs depending on the attachment site of the muscle. Since the action of the hamstrings occur in the sagittal plane and the anterior and posterior inclination of the pelvis also occurs in the sagittal plane, a significant result was shown, and since the left and right lateral inclination occurred in the frontal plane it was thought that an insignificant result was shown.

When the results of this study were combined, there was no statistically significant difference between the three groups in hamstring flexibility, QVAS, and pelvic anterior and posterior inclination variables, but a larger amount of change in the posterior pelvic inclination group was confirmed. This is thought that there was a larger change in the PPT group because the hamstring muscle shortening was strong due to the coupling action in the pelvis.

However, in the pretest of this study, the difference in the number of participants did not show a significant difference in hamstring flexibility between the three groups.

This study had the following limitation in explaining the results of this study. In evaluating pelvic mobility, the chair was held with both hands to minimize the movement of the trunk. At this time, there were many participants who had stated that their posture was unnatural because the arm 
length of each participant was not taken into account, which could affect the evaluation result.

In the future, if a device that reliably fixes the trunk and does not interfere with pelvic movements by supplementing the limitations of this study is developed and added, the methods used render greater accuracy and be more widely applied.

In conclusion, this study was conducted to investigate for the effect of self-stretching of the hamstring muscles according to the pelvic inclination of patients with low back pain.

As a result, although not statistically significant, there was a difference in the amount of change between the three groups. In particular, it was confirmed that the PPT group showed a relatively large amount of change in hamstring flexibility, QVAS, and pelvic anterior and posterior inclination variables.

Through this, self-stretching of the hamstrings can be expected to have a great effect when the pelvis is inclined posteriorly. Furthermore, therapists can expect different effects even when applying interventions to patients with low back pain, and can be applied in consideration of the participant's pelvic displacement.

\section{Conflict of Interest}

The authors declared no potential conflicts of interest with respect to the authorship and/or publication of this article.

\section{References}

1. Panjabi M, Yamamoto I, Oxland T, Crisco J. How does posture affect coupling in the lumbar spine? Spine 1989;14:1002-11.

2. Lee KW. Therapeutic exercise in low back pain. J Korean Acad Rehabil Med 1995;19:1

3. Myers TW. The superficial back line. In: Myers TW, editor. Anatomy trains. 2nd ed. Edinburgh: Churchill Livingstone/ Elsevier; 2009. p. 73-95.

4. Oh YT. Effect of hold-relax technique for college students with hamstring shortening. J Korean Soc Phys Med 2013;8:433-41.

5. Congdon R, Bohannon R, Tiberio D. Intrinsic and imposed hamstring length influence posterior pelvic rotation during hip flexion. Clin Biomech (Bristol, Avon) 2005;20:947-51.

6. Hartig DE, Henderson JM. Increasing hamstring flexibility decreases lower extremity overuse injuries in military basic trainees. Am J Sports Med 1999;27:173-6.

7. Jones MA, Stratton G, Reilly T, Unnithan VB. Biological risk indicators for recurrent non-specific low back pain in adolescents. Br J Sports Med 2005;39:137-40.

8. Esola MA, McClure PW, Fitzgerald GK, Siegler S. Analysis of lumbar spine and hip motion during forward bending in subjects with and without a history of low back pain. Spine 1996;21:71-8.

9. Rok S, Wytrazek M, Bilski B. Efficacy of therapeutic exercises in low back pain surveyed in a group of nurses. Med Pr 2005;56: 235-9.

10. Halbertsma JP, van Bolhuis AI, Göeken LN. Sport stretching: effect on passive muscle stiffness of short hamstrings. Arch Phys Med Rehabil 1996;77:688-92.

11. López-Miñarro PA, Alacid Cárceles F, y Muyor Rodríguez JM. Comparison of spinal curvatures and hamstring extensibility between paddlers and runners. Rev Int Med Cienc Act Fís Deporte 2009;9:379-92.

12. López-Miñarro PA, Alacid F, Rodríguez-García PL. Comparison of sagittal spinal curvatures and hamstring muscle extensibility among young elite paddlers and non-athletes. Int Sport Med J 2010;11:301-12.

13. López-Miñarro PA, Alacid F. Influence of hamstring muscle extensibility on spinal curvatures in young athletes. Sci Sports 2010;25:188-93.

14. Shamsi M, Shahsavari S, Safari A, Mirzaei M. A randomized clinical trial for the effect of static stretching and strengthening exercise on pelvic tilt angle in LBP patients. J Bodyw Mov Ther 2020;24:15-20.

15. Hansson T, Bigos S, Beecher P, Wortley M. The lumbar lordosis in acute and chronic low-back pain. Spine 1985;10:154-5.

16. Evcik D, Yücel A. Lumbar lordosis in acute and chronic low back pain patients. Rheumatol Int 2003;23:163-5.

17. Kim BG, Yi SJ, Kang JD, Park RJ. Difference of lumbar lordosis in patients with low back pain and controls. J Kor Soc Phys Ther 2000; $12: 185-90$.

18. Christie HJ, Kumar S, Warren SA. Postural aberrations in low back pain. Arch Phys Med Rehabil 1995;76:218-24.

19. Kang KB, Ahn YJ, Kim YJ, Kim YB, Park SC. Changes in sagittal spinopelvic parameters according to pelvic incidence in asymptomatic old Korean men. J Korean Soc Spine Surg 2011; 18:223-9.

20. Levine D, Whittle MW. The effects of pelvic movement on lumbar lordosis in the standing position. J Orthop Sports Phys Ther 1996;24:130-5.

21. Cameron DM, Bohannon RW. Relationship between active knee extension and active straight leg raise test measurements. J Orthop Sports Phys Ther 1993;17:257-60.

22. Reurink G, Goudswaard GJ, Oomen HG, Moen MH, Tol JL, Verhaar JA, et al. Reliability of the active and passive knee extension test in acute hamstring injuries. Am J Sports Med 2013; 41:1757-61.

23. Yang JH. A study of pain, depression and self-efficacy according to the classifications of pain among chronic pain patients. $\mathrm{J}$ Korean Acad Adult Nurs 2004;16:202-10.

24. Boonstra AM, Schiphorst Preuper HR, Reneman MF, Posthumus JB, Stewart RE. Reliability and validity of the visual analogue scale for disability in patients with chronic musculoskeletal pain. Int J Rehabil Res 2008;31:165-9.

25. Joo MK., Kim TY, Kim JT, Kim SY. Reliability and validity of the Korean version of the fear-avoidance beliefs questionnaire. Phys Ther Korea 2009;16:24-30.

26. Kim DY, Lee SH, Lee HY, Lee HJ, Chang SB, Chung SK, et al. Validation of the Korean version of the oswestry disability index. Spine 2005;30:E123-7. 
27. Jung SH, Park DS. Reliability and validity of the measurement of pelvic movement in low back pain patients using cushion sensor in sitting position. J Korean Soc Phys Med 2020;15:83-91.

28. Handel M, Horstmann T, Dickhuth HH, Gülch RW. Effects of contract-relax stretching training on muscle performance in athletes. Eur J Appl Physiol Occup Physiol 1997;76:400-8.

29. Bandy WD, Irion JM. The effect of time on static stretch on the flexibility of the hamstring muscles. Phys Ther 1994;74:845-50; discussion 850-2.

30. Kim JH, Kim TH. Immediate effects of stretching on hamstring stiffness. J Kor Soc Phys Ther 2010;22:1-7.

31. Jo M, Kwon N, Park S, Seo D, Jung J, Ha M, et al. Effects of the stretching exercise of hamstring muscle on flexibility and foot pressure in subjects with and without pelvis neutral position. $\mathrm{J}$ Korean Soc Integr Med 2016;4:31-9.

32. Bandy WD, Irion JM, Briggler M. The effect of static stretch and dynamic range of motion training on the flexibility of the hamstring muscles. J Orthop Sports Phys Ther 1998;27:295-300.

33. Halbertsma JP, Mulder I, Göeken LN, Eisma WH. Repeated passive stretching: acute effect on the passive muscle moment and extensibility of short hamstrings. Arch Phys Med Rehabil 1999; 80:407-14.

34. Magnusson SP, Simonsen EB, Aagaard P, Dyhre-Poulsen P, McHugh MP, Kjaer M. Mechanical and physical responses to stretching with and without preisometric contraction in human skeletal muscle. Arch Phys Med Rehabil 1996;77:373-8.

35. Lee MH. Effects of the low back exercise program including a hamstring stretching on lumbar muscle strength and subjective pain in chronic low back pain patients [Master thesis]. Seoul: Korea National Sport University; 2007.

36. Han HI, Choi HS, Shin WS. Effects of hamstring stretch with pelvic control on pain and work ability in standing workers. $\mathrm{J}$ Back Musculoskelet Rehabil 2016;29:865-71.

37. Monga A, Singh S. Impact of back muscle functions, spinal range of motion and fear avoidance beliefs on disability in chronic non-specific low back pain. Hum Bio Rev 2013;2:46-55.

38. Attrey P, Yadav M, Singh S. Relationship between passive straight leg raising test and $\mathrm{V}$-sit and reach test in measuring the hamstring flexibility. Indian J Phys Educ Sports Appl Sci 2017; 7:23-30.

39. López-Miñarro PA, Muyor JM, Belmonte F, Alacid F. Acute effects of hamstring stretching on sagittal spinal curvatures and pelvic tilt. J Hum Kinet 2012;31:69-78.

40. Fritz JM, Irrgang JJ. A comparison of a modified Oswestry Low Back Pain Disability Questionnaire and the Quebec Back Pain Disability Scale. Phys Ther 2001;81:776-88.

41. Marshall PW, Mannion J, Murphy BA. Extensibility of the hamstrings is best explained by mechanical components of muscle contraction, not behavioral measures in individuals with chronic low back pain. PM R 2009;1:709-18.

42. Kim S, Kim JH, Kim YL, Lee SM. Comparison of pain, disorder, back performance, and psychological factors in patients with low back pain and radicular pain. J Phys Ther Sci 2018;30:127-31.

43. Nagrale AV, Patil SP, Gandhi RA, Learman K. Effect of slump stretching versus lumbar mobilization with exercise in subjects with non-radicular low back pain: a randomized clinical trial. J Man Manip Ther 2012;20:35-42.

44. Vogt L, Pfeifer K, Banzer W. Neuromuscular control of walking with chronic low-back pain. Man Ther 2003;8:21-8.

45. Kim GC, Hwang BG. Kinetic analysis on the lumbar at the trunk flexion according to the degree of hamstring flexibility of healthy adult. J Korean Soc Phys Med 2012;7:501-7. 